\title{
Adaptación al medio: cambios de proyectos iniciales en la prensa sefardí otomana
}

\author{
Cristina MarTínez-GÁLvez \\ Universität Basel \\ martinezgalvez.cristina@gmail.com \\ María SÁNCHEZ-PÉREZ \\ Universidad de Salamanca \\ mariasanchezperez@usal.es
}

Recibido: 7 de enero de 2015

Aceptado: 10 de mayo de 2015

\begin{abstract}
Resumen
Los inicios de la prensa sefardí se sitúan a mediados del siglo XIX, cuando el influjo de Occidente penetró en las comunidades sefardíes de Oriente. Los contenidos de estos periódicos eran muy diversos: obras de información general, pero también científicos, literarios, humorísticos, de tendencias políticas diferentes, etc. Estos periódicos se publicaron en diferentes lenguas, grafías y alfabetos. No obstante, los que aquí analizamos se publicaron en judeoespañol aljamiado: tres periódicos de Esmirna y tres de Salónica. A lo largo del trabajo estudiamos los diferentes obstáculos y dificultades a los que tuvieron que enfrentarse los directores y editores de esta prensa sefardí otomana para conseguir sacar adelante sus publicaciones.
\end{abstract}

Palabras clave: periodismo; siglos XIX y XX; sefardíes; prensa sefardí; Imperio Otomano; Salónica; Esmirna.

\section{Adaptation to the Environment: Changes in Initial Projects in Ottoman Shephardic Press}

\begin{abstract}
The origins of Sephardic press date back to the mid- $20^{\text {th }}$ century, when the influence of the Western world spread across the Sephardim communities of the East. The content of these newspapers was diverse: pieces of general interest, but also scientific, literary and humorous works, with various political orientations. These papers were published in different languages, writing styles and alphabets. Those to be analysed here, however, were published in aljamiado Judeo-Spanish: three papers from Smyrna and one from Salonica. Throughout this work we will focus on the different obstacles and difficulties the editors and publishers of this Ottoman Sephardic press had to face to bring their publications to light.
\end{abstract}

Key words: journalism; nineteenth and twentieth centuries; Sephardim; Sephardic press; Ottoman Empire; Thessaloniki; Smyrna.

\section{Referencia normalizada}

Martínez-Gálvez, C., Sánchez-Pérez, M. (2015). Adaptación al medio: cambios de proyectos iniciales en la prensa sefardí otomana. Historia y Comunicación Social. Vol. 20, número 1, páginas 67-87. 
Sumario: 1. Introducción. 2. Periódicos de Esmirna. 2.1. Sha'aré Mizrha. 2.2. La buena esperanza. 2.3. El Mazaloso. 3. Periódicos de Salónica. 3.1. La Époka literaria. 3.2. Nuevo Avenir. 3.3. La solidaridad Ovradera. 4. Conclusiones. 5. Glosario. 6. Referencias bibliográficas.

\section{Introducción}

El inicio de la prensa periódica en judeoespañol se sitúa a mediados del siglo XIX, cuando el tradicional mundo sefardí empezó a abrirse al influjo de Occidente. Desde 1845 -fecha del primer periódico sefardí que conservamos, Sha'aré Mizrah [heb. 'puertas de Oriente'] - hasta la Segunda Guerra Mundial fueron cientos los periódicos sefardíes que vieron la luz en diferentes ciudades del mundo, aunque dos terceras partes se publicaron en Salónica, Constantinopla, Sofía y Esmirna. Pero también se imprimió y consumió prensa periódica en judeoespañol en otros muchos lugares donde hubo comunidades sefardíes, como Sarajevo, Ruse, El Cairo, Jerusalén, Viena, París, Nueva York, Los Ángeles, etc. En la actualidad, los repertorios bibliográficos recogen más de trescientos periódicos (es imprescindible el catálogo de Gaon 1965). Iacob M. Hassán, en un fundamental artículo-reseña, establecía tres etapas clave en la vida de la prensa sefardí: a) desde 1845 hasta la Revolución de los Jóvenes Turcos (1908); b) desde 1908 hasta la Segunda Guerra Mundial -que supuso un golpe mortal para la realidad judía y, por tanto, también para el periodismo-; y c) desde 1945 hasta nuestros días (Hassán 1966).

Todos esos periódicos eran de diferente carácter y duración. Los contenidos eran también muy diversos: desde periódicos destinados a la información exclusivamente hasta publicaciones humorísticas y satíricas. Además, conservamos también, como es obvio, publicaciones de tendencias políticas diferentes -sionistas, socialistas, etc.-. Aunque la mayor parte de esa prensa sefardí se publicó en judeoespañol aljamiado, también existen periódicos en caracteres latinos e incluso en otras lenguas -como por ejemplo en hebreo o en francés-. Por lo tanto, se utilizaron distintas grafías y alfabetos.

A partir de la década de los 60 del pasado siglo XX empezaron a producirse los primeros estudios en torno a la prensa sefardí, de ahí que, por ejemplo, Michael Molho en su libro sobre la literatura de los sefardíes de Oriente incluyera un apartado dedicado a esta prensa (Molho 1960, especialmente págs. 327-337 y 351-356). Actualmente, se trata de una línea de investigación que cuenta, cada vez, con estudios más numerosos. Existe una panorámica de la prensa periódica sefardí en Romero 1992 (capítulo 5) y diversas investigaciones en torno a esas publicaciones, desde diferentes ángulos (sobre la prensa y los demás géneros adoptados, Borovaya 2012).

Algunos de los primeros estudios se centraron en esa prensa como fuente de diversos materiales literarios (Romero 1979 y 1983; Savariego y Sánchez-Boudy 1987; Barquín 1993 y 1997a; Bunis 1999a y 1999b; Barquín 2000), pero también existen trabajos monográficos sobre determinados periódicos (por ejemplo, Barquín 1997b; Schmid 2003; Díaz-Mas y Barquín 2007; Martínez-Gálvez 2009, Sánchez-Pérez 2011 
y 2014 o Rieder-Zelenko 2013). Contamos también con estudios sobre la historia del periodismo en el Oriente Mediterráneo y en América (Angel 1982; Benbassa 1986; Arbell 1996; Shaul 1996; Ayoun 1997 y 1999; Ben-Ur 2001; Nassi 2001; Kerem 2003; Gerson Sarhon 2007; Grosman 2007; Güleryüz 2007; Romero 2007).

Existen también trabajos en los que se examinan determinadas informaciones en la prensa judeoespañola (Ares Yanez 1998; Asenjo 2005; Lochow-Drüke 2007; Morcillo 2007) o también sobre el papel de la prensa en la sociedad sefardí, fundamentalmente como contribución al progreso y modernización de los judíos (Abrevaya Stein 2004; Díaz-Mas y Sánchez-Pérez 2010, especialmente págs. 139-202; Studemund-Halévy, Liebl y Vučina 2013, especialmente págs. 15-202). Contamos también con estudios en torno a las características internas de estos periódicos (Bunis 199093; Bürki 2006). Con todo, queda aún mucho camino por explorar.

Ya se ha destacado en otras ocasiones la gran importancia que tuvo el periodismo para la evolución de las diferentes comunidades sefardíes (Romero 1992: 179) y, al mismo tiempo, las dificultades que tuvieron que superar quienes se propusieron tenazmente sacar adelante sus publicaciones, con la frecuente intención de contribuir con ello al desarrollo de sus comunidades y de sus propios correligionarios. Entre esos obstáculos que hubo que superar, algunos de ellos se debieron a causas internas, como fueron las propias dificultades que los sefardíes tenían para leer esos periódicos, pues existían quienes no entendían con claridad lo que allí se decía, ya que muchos de ellos no estaban habituados a este tipo de lectura y, en un principio, constituían "la más grande parte del puevlo: [...] los ke no estavan uzados aínda a meldar djornales" (Nuevo Avenir, 1909, pág. 1, col. a).

De este problema son testigos las propias páginas de los periódicos, que se esforzaban por ofrecer entre sus contenidos todo aquello que atrajera la atención de sus potenciales lectores y compradores. De ahí también la multiplicidad de publicaciones que hemos conservado, ya que existen periódicos de contenido muy diverso. Como veremos, las dificultades a las que debieron enfrentarse son de diverso signo, incluso hemos llegado a conservar periódicos que fueron fruto de una iniciativa individual, como El Luzero de la Pasensia, que se publicó en Turnu-Severin (Rumanía) en la década de 1880 (Díaz-Mas y Barquín 2007; Martínez-Gálvez 2009; y Díaz-Mas y Martínez Gálvez 2013) o que no salieron nunca de una imprenta, sino que se realizaron de manera manuscrita y mecanoscrita, de forma totalmente artesanal, como $E l$ Mesajero/The Messenger, que fue el órgano de expresión de una de las comunidades sefardíes de Los Ángeles (California) en la década de 1930 (Díaz-Mas y Sánchez-Pérez 2012 y 2014); todo esto nos revela el empeño de personas o comunidades por sacar adelante sus publicaciones.

Dentro de esas dificultades que hemos denominado 'internas' cabe destacar también cómo muchos de los directores de estos periódicos tuvieron que enfrentarse a la contrariedad que suponía sacar a la luz y continuar sus publicaciones con muy pocos recursos económicos, pues la mayor fuente de ingresos, además de la posterior incorporación de la publicidad, eran las suscripciones. Esto suponía una dificultad 
añadida, ya que no se trataba solo de conseguir los suficientes abonados, sino también de lograr que estos pagaran las suscripciones puntualmente. Por motivos como estos, muchos de esos periódicos tuvieron una breve duración y dejaron de publicarse por la falta de respuesta de sus lectores.

Frente a este tipo de causas, hubo otras externas relacionadas con la propia vida de las comunidades sefardíes en el Imperio Otomano, aunque, sin duda, la más destacable fue la férrea censura que impuso el sultán Abdul Hamid II desde 1878 -dos años después de su llegada al poder- hasta su derrocamiento con la revolución de los Jóvenes Turcos, en $1908^{1}$.

Algunos de estos problemas pueden verse reflejados en los ejemplos que queremos mostrar aquí. Se trata de verdaderas adaptaciones al medio, pues muchos de estos directores, impresores y redactores de periódicos tuvieron que cambiar su proyecto inicial en algún determinado momento. En la mayor parte de las ocasiones lo que encontraremos es la modificación de una iniciativa previa, es decir, por diversas causas, los autores tuvieron que concluir con sus publicaciones y, tras un período de tiempo, decidieron retomar aquella propuesta anterior, aunque con variaciones ${ }^{2}$.

\section{Periódicos de Esmirna}

\subsection{Sha'aré Mizrah}

Comenzaremos nuestro recorrido en Esmirna, con el periódico Sha'aré Mizrah (heb. 'puertas de Oriente') (Gaón 1965: núm. 290), que supone la primera manifestación de la prensa escrita sefardí. Con los datos que tenemos en la actualidad, sabemos que los inicios del periodismo sefardí tuvieron lugar en esta ciudad turca. Allí, en 1842 se gestó la idea de publicar La Buena Esperansa (Gaón 1965: núm. 43), dirigido por Refael Uziel Pincherle ${ }^{3}$, pero este proyecto nunca llegó a ver la luz por falta de apoyo logístico y de suscripciones (Cohen, en prensa). No obstante, el tesón de algunos de estos autores hizo que no desistiesen en su empeño y, por este motivo, el mismo Refael Uziel volvió a emprender la tarea de publicar tres años más tarde un nuevo periódico en judeoespañol: Sha'aré Mizrah (1845). El propio Refael nos describe la situación ${ }^{4}$ :

13 siván anyo 5602 (22 de mayo de 1842) publikí unos anejos por una gazeta ke deberá de ser puvlikada en lengua espanyola levantina kon el título de La Buena Esperansa. I la kavza de no kontin[u]ar la publikasión entonses fue por razón de los gastos treviles i los abonados ke tuve el onor de tener fueron tan pokos ke no kuvrían lo menos la mitad de los gastos (Sha'aré Mizrah, 30 kislev 5606 / 29 diciembre 1845, pág. 1).

De sus palabras no cabe señalar más que la evidencia: la falta de recursos económicos y los pocos abonados al periódicos fueron las causas por las que el proyecto de La Buena Esperansa no pudo finalmente salir adelante. Sin embargo, observando lo 
que ocurría entonces en otros países de su alrededor, él mismo señala que "oy, viendo ke la mankasa de dita koza en una nasión es muncho danyo para todo djeneral", (Sha 'aré Mizrah, 30 kislev 5606 / 29 diciembre 1845) decidió emprender de nuevo su tarea. Uziel, que fue el pionero al sacar a la luz el primer periódico judeoespañol del Imperio Otomano, es plenamente consciente, a mediados del siglo XIX, de que la difusión de la prensa periódica resulta un vehículo fundamental para el desarrollo de las comunidades, de los pueblos. Y de este modo lo expresa él mismo:

según lo estamos mirando kon nuestros [o]jos [en el] avantaje de todos las otras nasiones (avlo por munchas kozas ke elyos tienen de las ke amozotros mon mankan, komo ya se save). I la prima koza más interesada es la gazeta, según tiene el onor de azer s[a]ber su avantaje en poko tiempo, después de la publikasión de pokos núm[e] ros de su djornal (Sha 'aré Mizrah, 30 kislev 5606 / 29 diciembre 1845, pág. 2).

Sus palabras no pueden ser más expresivas, pues se muestra conocedor de las carencias que tiene la comunidad sefardí, de que es necesaria una modernización y dirigir la mirada hacia esos países que él considera más desarrollados, entre otras cosas, porque poseen ya una difusión establecida de prensa periódica. Parece que Uziel es plenamente consciente, además, de la dificultad "que entrañaba el arraigo de una nueva realidad (el periodismo) en una sociedad tan conservadora y tradicionalista como la sefardí oriental" (Díaz-Mas 2006: 194). Sin embargo, con esta nueva publicación, con Sha aré Mizrah, Uziel retoma su antiguo proyecto y, de este modo, afirma:

Vengo a renovar mi antiga idea sovre dito invento. Es[pero ke el] Dio estará ami ayuda i prosperaré en [una tarea] tan provechoza para toda la nasión, para [toda] klasa [...] munchas kozas provechozas i buenas para la nasión israelita. I avrirá puerta de luz i alelumbra[rá] [vacío] nuestros ermanos los morantes en la Turkía [...] La prezente gazeta ke venimos publikar le kitimos el número de La Buena Esperansa i venimos a darle el título de Sha 'aré Mizrah, o sea, 'puerta del Oriente'. (Sha 'aré Mizrah, 30 kislev 5606 / 29 diciembre 1845, pág. 2).

Parece que las intenciones de este editor se traslucen en los propios títulos de sus periódicos: la esperanza de enraizar el fenómeno de la prensa periódica en la comunidad sefardí de Esmirna, al tiempo que su país, Turquía, sirviera de "puerta entre occidente y oriente", de lugar de tránsito por el que accederían las novedades de occidente a las comunidades sefardíes del Imperio Otomano.

\subsection{La Buena Esperanza}

Sin salirnos de la localidad de Esmirna, unas décadas después, Aarón Iosef Hazán ${ }^{5}$, con apenas veinte años, coge el testigo de Refael Uziel y en 1871 funda en Esmirna el periódico La Esperansa (Gaon 1965: núm. 17) que, posteriormente, cambiará su nombre por el de La Buena Esperansa, cuyo título permaneció ya inalterado hasta la desaparición del periódico, en 1917, con lo que nos encontramos con una de las publicaciones periódicas más longevas en Esmirna (para más datos sobre este periódico, véanse Rieder-Zelenko 2008 y 2013; y Saba-Wolfe 2010). 
De acuerdo con los datos que recoge Gaon, La Esperansa apareció en 1871 con un escaso período de vigencia de un año. En 1874, Hazán retomó su proyecto que, al principio, siguió denominándose como su anterior semanal, La Esperansa, y que, con el paso de los años se le añadió el adjetivo de 'buena', concretamente en el núm. 268 del año VI (30 shebat 5640 / 12 febrero 1880).

Tal y como le había ocurrido años antes a Refael Uziel, en la década de los setenta del siglo XIX Aarón Iosef Hazán volvió a enfrentarse a los mismos problemas que su predecesor: la falta de financiación a la hora de mantener viva su publicación. De sus palabras se deducen las dificultades que encontraron en 1871:

dezde ke nozotros tuvimos deshado, atrás dos anyos, la publikasión de nuestro djornal La Esperansa, ke una partida de nuestros korelidjionarios nos izieron las keshas las más grandes porke kedimos de nuestra ovra, aun ke ya entendieron ke lo fuimos forsados; i otros munchos más, tanto de nuestros kompatriotos komo los munchos amigos de la literatura de otras sivdades, nos rogan, nos enkorajan, nos prometen de ayudarnos kon todas sus posivilidades porke torna puvlikemos el djornal. I nozotros, por azer gusto de nuestros amigos i amigos de la literatura, aprevamos otra vez. (La (Buena) Esperansa, 27 tishrí 5635 / 8 octubre 1874, pág. 1, col. A).

Eran muchas, por tanto, las dificultades que encontraron estos primeros editores y fundadores de publicaciones periódicas en el Imperio Otomano. Sin embargo, la fuerza y el tesón de algunos hombres como Uziel o Hazán hicieron que la prensa sefardí diera sus primeros pasos a mediados del siglo XIX. Sefardíes voluntariosos que, con la ayuda de aquellos correligionarios que apreciaban los beneficios de estas publicaciones, decidieron adoptar e implantar en su cultura aquellos géneros occidentales que tanto harían florecer la cultura sefardí a partir de aquellos años. Fueron hombres que, sin duda, supieron adaptarse al medio en el que se encontraban para superar las dificultades y obstáculos que se interpusieron en su carrera.

\subsection{El Mazalozo}

Otro periódico de Esmirna fue El Mazalozo, cuyo director fue Alexandre Ben-Guiat ${ }^{6}$. Señalaba Elena Romero:

El activo traductor y editor de novelas Alexander Ben-Guiat estuvo muy ligado a las labores periodísticas. Inició sus andaduras en este campo con La Verdad (1884) [...]. Años después dio vida al longevo El Meseret (1897-1920), donde aparecieron numerosas novelitas traducidas y adaptadas al francés por el propio Ben-Guiat [...] El activo Ben-Guiat no se conformó con un solo periódico, sino que en sus 65 años de vida dirigió también El Maźalośo (Romero 1992: 181).

El primer número que hemos conservado de El Mazalozo (Gaon 1965: 161) se publicó el 8 heshván 5669 (2 noviembre 1908) con la siguiente indicación "Djornal de todos i para todos. Aparese el lunes i el miércoles"; sin embargo, solamente dos meses después, Ben-Guiat decide dar un cambio de rumbo a su publicación. En primer lugar, cabe destacar las transformaciones que sufrió la cabecera, ya que aparecía el título en turco otomano, judeoespañol y en letras latinas -por este orden-, la dirección se escribía solo en letras árabes y el subtítulo -que no tuvo en un princi- 
pio- era "Jornal sientífiko i literario, aparesiendo kada viernes". Por lo tanto, con los datos de que disponemos, podemos observar que el primer número responde a una línea editorial que, por motivos que desconocemos, Alexander Ben-Guiat decidió no seguir. El cambio de diseño en la portada, la inclusión de un nuevo subtítulo y la declaración explícita de intenciones en el siguiente número que hemos conservado ponen de relieve que el editor del periódico había realizado un cambio de dirección en su publicación. El propio Ben-Guiat explica:

Este es el segundo número del Mazalozo transformado. Komo la semana pasada ${ }^{7}$, i en esta también, nozotros vamos estar kontinuando de ir mandándolo onde bueno nos está paresiendo: a abonados, a konosidos i a non-konosidos [...] Es solamente la semana venidera ke nozotros empesaremos a saver kén son nuestros abonados, i a kén kale ke mandemos [...] El kontenido del Mazalozo va ser siempre polítiko, en el djénero del artíkulo ke meldaron la semana pasada [...] Trataremos igualmente de literatura i sensia i, según lo tuvimos dicho, a ningún presio no publikaremos akí polémikas ni avizos. (El Mazalozo, 29 tebet 5669 / 22 enero 1909, pág. 1, col. A).

Recordemos que cuando Ben-Guiat decide sacar a la luz esta nueva publicación tiene ya unos veinticinco años de experiencia como editor y director de varios periódicos y suplementos, por lo tanto el cambio de orientación que sufre el periódico es posible que se debiera más a motivos de contenido que comerciales: en primer lugar, porque se declaran abiertamente los primeros a partir de ese número conservado en 1909, y se amplía su variedad con respecto a los contenidos del primer número, de corte estrictamente político, seguramente para atender a un sector del público más amplio -"El Mazalozo va ser siempre polítiko [...] Trataremos igualmente de literatura i sensia"-, y en segundo lugar, porque parece que no existían problemas de solvencia en cuanto al mantenimiento del periódico, pues se declara: "El abonamiento asta fin de elul venidero es solamente de un medjedié 8 pagable una semana después de Shavuot".

Por lo tanto, si echamos unas cuentas muy simples comprobaremos que el periódico se publica en el mes de tebet y los abonados podían realizar sus pagos en siván, es decir, Ben-Guiat dejaba un plazo de más de veinte semanas para fiar el crédito. No solo eso, sino que voluntariamente el periódico renuncia a la publicidad, una de las fuentes de ingreso más importantes de la prensa: "i, según lo tuvimos dicho, a ningún presio no publikaremos akí polémikas ni avizos" (El Mazalozo, 1909, pág. 1, col. A). Además de estos datos, recordemos que, por aquellas mismas fechas, Ben-Guiat publica también El Kismet de Martes, El Kismet Poeta-ambos suplementos cómicos de El Mazalozo- y el periódico El Soitarí, por lo que, con estas premisas no podemos sino deducir que parece poco probable que el cambio de rumbo del periódico El Mazalozo se debiera a problemas económicos, frente a lo que hemos visto en los ejemplos anteriores. 


\section{Periódicos de Salónica}

\subsection{La Époka Literaria}

A continuación queremos mostrar otros ejemplos que se produjeron en la ciudad de Salónica que, recordemos, fue el enclave geográfico donde más publicaciones en judeoespañol vieron la luz desde 1865 hasta la Segunda Guerra Mundial. Comenzaremos por el caso del periódico La Époka Literaria (Gaon 1965: 23), suplemento literario de La Époka:

Importante papel en la prensa de Salónica desempeñó la familia Haleví. El patriarca y famoso coplero Sa adi Haleví fundó en 1875 La Época, "revista política, comercial y literaria", de talante liberal y uno de los más importantes y longevos periódicos de la ciudad [...] En La Época trabajó también Eliyahu Šem-Tob Arditti, que fue director del suplemento La Época Literaria así como de la nueva serie del periódico iniciada en 1908. (Romero 1992: 184) ${ }^{9}$.

El periódico La Époka Literaria de 1908 se abría con la indicación "nueva seria", en el sentido de "nuevo suplemento", ya que este ejemplar es el segundo intento de publicar un fascículo literario del periódico La Époka (véase Bürki 2010), ya que la primera tentativa se realizó, bajo el mismo título y los mismos responsables, en 1906, tal y como indica Gaon (1965: 22). Antes de adentrarnos en los contenidos de $\mathrm{La}$ Époka Literaria cabe destacar algunos aspectos que se señalaban en la cabecera. En primer lugar nos referiremos a los datos relativos al precio del periódico. Ya en este primer número (23 iyar 5668 / 24 mayo 1908) aparecía la siguiente tabla:

$$
\text { [col. A] Abonamientos: }
$$

Saloniko

Provinsias

$$
\begin{array}{ll}
\text { Un anyo } & \text { Sesh mezes } \\
25 \text { groshes } & 13 \text { groshes }
\end{array}
$$

Estraniero

$$
30 \text { groshes } 15 \text { groshes }
$$

35 groshes 18 groshes

[col. B] Abonamientos. Para los abonados de La Époka un anyo:

Saloniko: 20 grosh.

Provinsias: 25 grosh.

Estraniero: 30 grosh.

Es decir, la indicación "Para los abonados de La Époka un anyo" se refiere a los abonados del periódico dirigido por Sam $\operatorname{Levy}^{10} \mathrm{y}$, por lo tanto, quienes ya pagaban suscripción a esa publicación recibían una rebaja en el precio del suplemento literario. Además, en la misma portada de este primer número se indicaba también que "Este 
número es dado debaldes", es decir, gratis. El hecho de que este número se repartiera sin coste adicional para el lector-comprador es un claro ejemplo de mecanismo de marketing y captación de público. Una vez cumplido este objetivo, en los siguientes números desapareció esta indicación, siendo obligatorio el pago del suplemento para adquirirlo. De hecho, a partir del segundo número se señala claramente: "Pagamientos antichipado". De este modo parece que, tanto el "propietario-konsesionario" -B. Saadi de Haleví- como el "redaktor-administrador" -Eliyahu Shem Tob Arditi ${ }^{11}$ habrían querido cubrirse las espaldas para no tener problemas pecuniarios, ya que, como hemos señalado, o bien los pagos se hacían por adelantado o bien a través de "abonamientos" ('suscripciones').

Respecto a los contenidos de La Époka Literaria cabe señalar algunos aspectos importantes. El primer número se abría con una pomposa alabanza hacia el sultán Abdul Hamid II:

En el punto ande la prensa empesa a estampar el primo número de La Époka Literaria, muestro penserio se abol[t]a sovre el augusto trono de muestro manyánimo soverano, su maestad imperial Gazi sultán Abdul Hamid 2º grasias a la alta proteksión del kual mos es dado de pueder empesar oy esta nueva puvlikasión.

Nuestra rekonosensia por el gloriozo monarka de los osmanlís, a kien los djudiós devemos tantos bie[ne]chos, es sin límito. En esta ora sovre todo, ande, kon la aparisión de La Époka Literaria, suvimos un nuevo eskalón en la grande eskalera del progreso. Muestros korasones se inchen de entusiasmo en pensando de kuántas i kuáles favores no somos nozotros devdores eskuentra el más grande i el más djenerozo delos soveranos.

Es kon grande umildansa i kon el más alto respekto ke mos permitimos de sotometer nuestros omajes al pie del trono imperial i de gritar del fondo de muestra alma: ¡Padishaimiz djok yasha! ${ }^{12}$. (La Époka Literaria, 23 iyar 5668 / 24 mayo 1908, pág. 1, col. A).

El texto no puede ser más expresivo, pues se declara abiertamente la intención de caer en gracia al sultán y granjearse su buena voluntad hacia la publicación. No hay que olvidar que, debido a la férrea censura que estableció Abdul Hamid II durante más de treinta años, era necesaria la obtención de numerosos permisos (firmán, en turco) para la licencia de la publicación (Romero 2007: 19). Se trata de una típica captatio benevolentiae para tratar de zafarse y evitar la censura que estableció quien fue el último sultán otomano poseedor de poderes absolutos y que fue obligado a renunciar a dicho absolutismo y aceptar la Constitución con la sublevación de los Jóvenes Turcos el 24 de julio de 1908, justamente dos meses después de la aparición de esta alabanza en La Époka Literaria (24 de mayo de 1908).

El hecho de que encontremos un editorial de estas características en esta publicación contrasta con la libertad de expresión que se impuso a partir de la revolución de los Jóvenes Turcos y que permitió poder sacar a la luz publicaciones de diversa índole -como podremos ver más adelante- que hubieran sido imposibles publicar unos años antes y que vinieron a contribuir a que a partir de entonces podamos asistir 
a un período de tiempo que ha sido considerado la edad de oro del periodismo sefardí (Hassan 1966: 230).

Volviendo a los contenidos de La Époka Literaria, al no haber una declaración explícita de intenciones en el primer número, B. Saadi de Haleví y Eliyahu Shem Tom Arditi se vieron obligados a concretarlos en el segundo número, debido a la demanda de sus propios lectores:

Muchos amigos mos demandan de eksponer un programa. Los satisfazemos súbito: La Époka Literaria no va azer ni senyales ni maravías.

No tenemos grandes ambisiones. Antes de todo, keremos ser modestos, no prometer mucho i tener poko. Es lo kontrario de esto ke dezeamos azer. No pretendemos djugar un grande rolo en la vida sosiala de nuestro puevlo. Mos vamos esforsar de introdusir entre muestras familyas el gusto delas lecturas sanas, en mizmo tiempo agradavles ke provechozas. No vamos azer un djornal de informasiones polítikas ni komersiales, ma una puvlikasión eskluzivamente literaria, ke interese a todos i pueda ser metida entre todas las manos. (La Époka Literaria, 1 siván 5668 / 31 mayo 1908, pág. 1, col. A).

Con todo, el interés principal de La Époka Literaria, tal y como declara el propio nombre del periódico, será cualquier tema relacionado con la literatura, de ahí la aparición, entre sus páginas de "romansos, novellas, [ku]entos, poezías", junto con "variedades, kuriozidades", etc. De este modo, como ocurrió con otros periódicos en judeoespañol -de Turquía y los Balcanes, pero también de otros lugares del mundosus editores elegían determinados contenidos con el propósito de fidelizar e instruir a un determinado público sefardí y, al mismo tiempo, parece evidente que la creación de unos suplementos -y la relación de estos con sus correspondientes periódicospone de relieve la necesidad de seleccionar determinados materiales para una u otra publicación (como ejemplo similar puede verse Sánchez-Pérez 2011).

\subsection{Nuevo Avenir}

Prestaremos atención ahora a otra publicación salonicense de principios del siglo XX: el caso del periódico Nuevo Avenir (Gaon 1965: 197). Como sabemos, a finales del siglo XIX, concretamente en 1897 se funda en Salónica uno de los periódicos de mayor impacto y longevidad, El Avenir (Gaon 1965: 2), de tendencia sionista, de la mano de David Isaac Florentín (remitimos de nuevo a Bürki 2010) ${ }^{13}$. Pocos años después, en 1909, comienza a publicarse Nuevo Avenir -suplemento del periódico anteriormente citado-, cuyo título cambió a partir del sexto número, pasándose a llamar Revista Popular, con el fin de evitar confusiones entre El Avenir y Nuevo Avenir $^{14}$. Este último apareció el 2 elul 5669 (19 agosto 1909) de forma gratuita, de nuevo en un intento de conseguir fidelizar a un determinado público sefardí, aunque se declaraba expresamente en la cabecera que los "abonamientos se pagan de antes", probablemente con el fin de asegurarse su publicación.

En el primer número se explica ya que la aparición de Nuevo Avenir es un nuevo intento por publicar un suplemento que había fracasado anteriormente: 
Ay ocho anyos, un grupo de mansevos entre los kualos se topavan diversos profesores i el sotoskrito avía tomado la inisiativa de puvlikar un chiko djornal de interés turavle, una revista popular [...] Por kavzas independientes de su veluntad, akeos bravos mansevos no pudieron kontinuar sus ovra [...] El Nuevo Avenir perkurará de enchir akel lugar kedado vazío. (Nuevo Avenir, 2 elul 5669 / 19 agosto 1909, pág. 1, col. A].

David Isaac Florentín se refiere a su publicación salonicense El Avenir. Revista popular puvlikada por la "Ovra de Puvlikasiones Israelita”, en la que él mismo formaba también parte de la redacción. Tanto en la mención de Gaon (1965: 3) como en los números que hemos podido consultar, el ejemplar más antiguo conservado es el número 4 (23 kislev 5662/4 diciembre 1901). Esta revista aparecía cada miércoles, con frecuencia semanal y se trataba de un suplemento que se ofrecía gratis para los abonados del periódico El Avenir.

El Nuevo Avenir vino, por tanto, a sustituir el intento fallido de ese primer suplemento, manteniendo gran parte de sus características, como por ejemplo su tamaño (según Gaon, de 16:24) o los precios, ya que apenas varían excepto en el caso de la venta en la propia Salónica, que se redujo de 12,50 groshes a 12,20. Teniendo en cuenta, además, la declaración de intenciones de este primer número se dice que en Nuevo Avenir intentará: "informar, divertir, azer pensar, despertar" (Nuevo Avenir, 2 elul 5669 / 19 agosto 1909, pág. 1, col. A).

En este sentido, tanto el periódico como el suplemento mostrarían contenidos de diverso signo, muchas veces en relación con la ideología sionista de su propietario, David Isaac Florentín, quien se convirtió en una figura clave del movimiento sionista griego hasta su emigración a Israel en 1926.

\subsection{La Solidaridad Ovradera}

De orientación contraria es la publicación salonicense La Solidaridad Ovradera (Gaon 1965: 208), que representa la alternativa política en Salónica al sionismo: el socialismo (Martínez-Gálvez 2010: 172). Los movimientos obreros comenzaron a tener cabida en Salónica poco después de la revolución de los Jóvenes Turcos:

Salónica era la ciudad más avanzada industrialmente de los Balcanes otomanos y, después de 1908, nació un movimiento obrero vigoroso, dirigido principalmente por intelectuales judíos y búlgaros. Se puso a la cabeza de la nutrida clase trabajadora de la ciudad y en poco tiempo se volvió tan activo y militante que pasó a ser la principal preocupación política de los nuevos amos de Salónica, quienes, como los demás ciudadanos asombrados, tuvieron que familiarizarse con el espectáculo de las manifestaciones sindicales, las sentadas, las huelgas, los cierres y los desfiles (Mazower 2009: 331)

Una publicación de este tipo, de marcado carácter político e ideológico, hubiera sido imposible sin el derrocamiento en 1908 de Abdul Hamid II. Precisamente los nuevos aires de libertad permitieron que los movimientos obreros pudieran articularse, comenzar a luchar por la mejora de sus condiciones de trabajo y, precisamente también por todo esto, los vehículos de expresión de estas tendencias políticas -folle- 
tos, periódicos, octavillas- pudieron imprimirse y publicarse en el Imperio Otomano. Es más:

Gran importancia tuvo en Salónica el desarrollo de la prensa política de tendencias sionistas y socialistas, que combatieron acremente entre sí y cuya lucha ideológica sobrepasó los límites locales para combatir las opiniones de periódicos de contraria ideología de otras ciudades (Romero 1992: 184) (15 $^{15}$.

La Solidaridad Ovradera apareció en Salónica el viernes 19 shebat 5671 (17 febrero 1911), después de que desapareciera el Djornal del Lavorador (1909), cuyo subtítulo era "Órgano de la Federación Socialista de Salonico". Gaon (1965: 92) no ofrece datos que expliquen el cambio de título, pero lo que sí parece evidente es que el periódico fracasó su andadura en un primer intento debido a la falta de recursos económicos. Este primer proyecto fue el Djornal del Lavorador, publicado en 1909 en cuatro lenguas (judeoespañol, griego, búlgaro y turco), que más adelante -y debido a una serie de crisis internas que acabaron con la deserción del componente búlgaro en la Federación - fue publicado únicamente en judeoespañol. Estas desavenencias internas, unidas al recrudecimiento del régimen de los Jóvenes Turcos, marcaron el fin de la bonanza para el socialismo salonicense y así también la interrupción de este proyecto editorial.

Más tarde, y gracias a una revitalización del movimiento y al acercamiento de posturas entre los socialistas de Salónica y los búlgaros, surgió La Solidaridad Ovradera como órgano de la renovada Federación (Dumont 2001: 201-204). La Federación Obrera Socialista de Salónica fue fundada por el sefardí Abraham Ben-Aroya -redactor de nuestra publicación- en $1909^{16}$. Dicha Federación, al ser reconocida por la II Internacional, emprendió la tarea de publicar el periódico, cuyos comienzos estamos analizando ahora.

Utilizando el tono propio de todas estas publicaciones de índole política -sefardíes o no- los redactores se muestran contundentes:

Esta es la segunda i última prova de la Federasión Sosialista (sosial israelita) de editar su órgano. Esta vez, la aparisión de La Solidaritá ya está asegurada más de un anyo. Muestro eskopo ya es konosido, i mientres toda la egzistensia del djornal ya vamos a tener a aklarar este eskopo i motivarlo. (La Solidaridad Ovradera, 19 shebat 5671 / 17 febrero 1911, pág. 1, col. A).

De sus palabras solo cabe deducirse que, en esta ocasión, la Federación Socialista de Salónica tomó sus debidas precauciones y, de este modo, se aseguraron previamente la subsistencia de la publicación durante, al menos, un año. El éxito fue rotundo y se invirtió en él mucha energía y esperanza, puesto que la primera tirada de La Solidaridad Ovradera contaba con unos 3.000 ejemplares, una cantidad nada desdeñable para la época (Dumont 2001: 205). Por los datos que conocemos, la publicación logró mantenerse y continuó publicándose durante años después, de hecho el rotativo La Solidaridad Ovradera:

lo cerró la censura militar en vísperas de la primera guerra mundial y fue sustituido poco después por Avante, que hasta 1923 tuvo como redactor a Abraham Ben-Aroya. 
En esa fecha la Organización Socialista de Salónica se convirtió en comunista y Ben-Aroya dejó sus tareas, siendo sustituido por Mac Ventura. El periódico desapareció en 1935 (Romero 1992: 185).

No obstante, según los datos que proporcionan Benbassa y Rodrigue cabe señalar lo siguiente:

Con sus periódicos, Jornal del Lavorador (1909-1910), Solidaridad ovradera -"Solidaridad obrera", 1911-1912-, Avanti -“Adelante", 1911-1934- que en 1912 tenían una tirada de más de cinco mil ejemplares, con sus folletos, y su formidable impacto sobre las masas trabajadoras, la Federación, alrededor de la cual giraban entre siete mil y ocho mil personas, llegaría a ocupar un lugar preponderante en la vida salonicense. (Benbassa y Rodrigue 2004: 308-309).

El periódico, por tanto, sobrevivió varias décadas porque en Salónica existió un arraigado movimiento socialista "vinculado directamente al componente judío de la ciudad" (Benbassa y Rodrigue 2004: 289). La irrupción de la modernidad en el Imperio Otomano a raíz de la revolución de los Jóvenes Turcos hizo que hubiese una creciente influencia de las nuevas ideas políticas provenientes de Occidente. Los sefardíes de Salónica no quedaron indiferentes ante estos hechos y muy pronto tomaron parte activa de esta agitación política ${ }^{17}$. Ya hemos mencionado cómo la prensa fue testigo de esos enfrentamientos entre las tendencias sionistas y socialistas y, en efecto, los movimientos de izquierda y derecha arraigaron pronto en la sociedad sefardí de Salónica.

En la primera década del siglo XX esta Federación Obrera Socialista de Salónica estuvo básicamente integrada por judíos -fundamentalmente trabajadores de la Compañía Tabacalera ${ }^{18}$, pero también artesanos, tipógrafos, estibadores del puerto, etc.- y, paulatinamente se fue produciendo un movimiento más hacia a la izquierda, comenzando por el socialismo y terminando en el comunismo. En buena medida este hecho se produjo debido al crecimiento del antisemitismo en Salónica ${ }^{19}$, que fue tomando fuerza progresivamente en las primeras décadas de la centuria y cristalizó en el pogromo de Camp Campbel1 ${ }^{20}$, provocado por grupos de inspiración fascista. Esa radicalización hacia la izquierda se expresa también en el cambio de orientación de nuestro periódico y cabe señalar como dato importante que ya en 1912 tenía una tirada de más de cinco mil ejemplares, desde luego una cifra nada desdeñable.

La desaparición del periódico parece estar en relación con las tensiones políticas de mediados de los años 30 y la subida al poder del dictador Ioannis Metaxás el 4 de agosto de 1936. La dictadura impuso el fascismo griego desde 1936 hasta 1941 y, de este modo, se eliminaron los partidos políticos. En el caso que estamos viendo, es importante señalar además que, especialmente los comunistas, sufrieron una represión brutal. Por lo tanto, la Federación Socialista nacida en Salónica y sus diferentes publicaciones como órgano de difusión tuvieron una vida de unos treinta años. Si las aspiraciones de modernización y los aires de libertad habían llegado a la "Jerusalén de los Balcanes" a principios del siglo XX, la dictadura de los años 30 y la posterior deportación y exterminio de los judíos en la Segunda Guerra Mundial, acabaron prácticamente con toda la comunidad sefardí de la ciudad de Salónica. 


\section{Conclusiones}

A través de estos ejemplos que hemos analizado de las ciudades de Esmirna y Salónica hemos podido comprobar que detrás de cada proyecto existen diferentes motivos que produjeron diversos cambios de orientación de unas determinadas publicaciones periódicas sefardíes ${ }^{21}$.

Entre los periódicos que hemos estudiado aquí, El Mazalozo de Esmirna es el único caso en el que el cambio de orientación de la publicación parece no responder a cuestiones económicas, como ya hemos visto anteriormente. Sin embargo, en la mayor parte de las ocasiones cabe deducir que la falta de financiación, es decir, la escasez de recursos económicos o los pocos suscriptores y abonados tuvieron como consecuencia que algunos periódicos no pudieran proseguir su andadura. Se trató de intentos fallidos de sacar adelante determinadas publicaciones, como es el caso de $L a$ Buena Esperansa de Refael Uziel Pincherle, en Esmirna, que más adelante apareció con otro título, Sha'aré Mizrah, o también El Djornal del Lavorador, de Salónica, que volvió a publicarse posteriormente con el título de La Solidaridad Ovradera, una vez que sus editores habían asegurado previamente la financiación necesaria para su publicación. En este sentido, con otros dos periódicos de la ciudad de Salónica, La Époka Literaria y Nuevo Avenir, sucedió algo parecido: sus editores decidieron proseguir con su proyecto cuando tuvieron la suficiente garantía y certeza de que podrían mantener la subsistencia de sus publicaciones durante un período determinado.

La falta de recursos económicos y la probabilidad de que hubiese pocos sefardíes que decidieran suscribirse a un periódico y pagar las consiguientes cuotas de abono responde, en buena medida, a la estrechez económica que sufrieron los países de Turquía y los Balcanes en las primeras décadas del siglo XX. El encarecimiento de los precios fue una realidad palmaria en la zona durante aquel período y ello provocó que muchos sefardíes se encontraran en un estado de acusada pobreza. Las circunstancias históricas y la serie de conflictos que afectaron a estos lugares - destronamiento de Abdul Hamid II, Primera Guerra Mundial, guerra turco-griega de 1919-1922, etc.- desembocaron en esta depresión económica: "como secuela de estas guerras y situaciones de crisis llega la miseria a las comunidades sefardíes y los judíos empobrecidos sufren de la terrible carestía y de la escasez de alimentos" (Weich-Shahak 2010: 226).

Con dichas premisas parece evidente que con estas dificultades resultara bastante complicado que algunas publicaciones sefardíes consiguieran salir adelante. No obstante, queda claro el tesón y la perseverancia de algunos editores, quienes perseveraron en su propósito de sacar a la luz estos periódicos y, de este modo, consiguieron hacer llegar a sus correligionarios no solo noticias e informaciones que afectaran a la propia vida de sus comunidades sino también de animarlos, entretenerlos y aleccionarlos con los contenidos de estas publicaciones. Se trataba, en definitiva, de ayudar al desarrollo de las comunidades sefardíes de oriente. 


\section{Glosario}

amozotros: 'a nosotros'; aprevamos: 'probamos'; avantaje: (fr. avantage) 'provecho, ventaja'; dito: 'dicho'; djornal: (it. gionarle, fr. journal) 'periódico'; elul: mes del calendario judío que en el gregoriano correspondería a los meses de 'agosto-septiembre'; enkorajan 'estimulan'; grosh: (tc. kuruş) 'moneda turca'; heshván: mes del calendario judío que en el gregoriano correspondería a los meses de 'octubre-noviembre'; iyar: mes del calendario judío que en el gregoriano correspondería a los meses de 'abril-mayo'; kale: 'hace falta, es indispensable'; kavza: 'causa'; kedimos de: 'dejamos de, abandonamos'; keshas: 'quejas'; kislev: mes del calendario judío que en el gregoriano correspondería a los meses de 'noviembre-diciembre'; kismet: 'destino, oportunidad, suerte'; kitimos: 'quitamos, sacamos'; korelidjionarios: 'correligionarios'; mankansa: (it. mancanza) 'falta'; mazalozo: (del hb. לזמ 'suerte') 'feliz, favorecido por el destino'; medjedié: 'moneda turca'; meldaron: 'leyeron'; morantes: 'habitantes'; omajes: (fr. hommage) 'homenajes'; osmanlís: (tc. osmanli) 'turcos, otomanos'; penserio: 'pensamiento' y por extensión 'preocupación'; perkurará: 'tratará de, procurará'; sensia: 'ciencia'; Shavuot: celebración religiosa judía que se celebra los días 6 y 7 del mes de siván en el que se conmemora la entrega de las Tablas de Ley por Dios a Moisés en el Monte Sinaí; shebat: mes del calendario judío que en el gregoriano correspondería a los meses de 'enero-febrero'; siván: mes del calendario judío que en el gregoriano correspondería a los meses de 'mayo-junio'; sivdades: 'ciudades'; sotometer: (it. sottomettere) 'someter, doblegar'; tebet: mes del calendario judío que en el gregoriano correspondería a los meses de 'diciembre-enero'; tishrí: mes del calendario judío que en el gregoriano correspondería a los meses de 'septiembre-octubre'; torna: 'de nuevo, otra vez'; terivles: 'terribles'; turavle: 'duradera'.

\section{Referencias bibliográficas}

ABREVAYA STEIN, Sarah (2004), Making Jews Modern: the yiddish and ladino press in the Russian and Ottoman Empires, Bloomington: Indiana Univ. Press.

ANGEL, Marc D. (1982), La América, The Sephardic Experience in the United States, Philadelphia: Jewish Publication Society.

ARBELL, Mordechay (1996), "El jurnalizmo sefaradi en Viena", Aki Yerushalayim 17, 54, págs. 24-25.

ARES YANEZ, Berta (1998), "La prensa en djudeo-espanyol i la kreasion del Estado de Israel", Aki Yerushalayim 19, 57, págs. 27-29.

ASENJO, Rosa (2005), "España y los sefardíes: el desastre del 98 en El Avenir", Sefarad 65, pp. 3-40 y 227-269.

AYOUN, Richard (1997), "La prensa djudeo-espanyola en Izmir antes de 1914”, Aki Yerushalayim 56, 18, pp. 40-42.

(1999), "Des Journaux Judéo-Espagnols à Izmir et à Salonique jusqu'à la veille de la première guerre mondiale", en R. Gatenio, ed., Internacional Conference, 
Judeo Espaniol: The Evolution of a Culture, Thessaloniki: Ets Ahaim Foundation, págs. 89-102.

BARQUÍN, Amelia (2007), "La problemática autoría de las novelas sefardíes: el caso de Alexandr Ben-Guiat", en Neue Romania 37 (=Judenspanish XI), pág. 27-47. (2000), "La prensa sefardí: fuente de materiales literarios", Ínsula 647, págs. $25-28$.

(1997a), Edición y estudio de doce novelas aljamiadas sefardies de principios del siglo $X X$, Leioa: Ediciones de la Universidad del País Vasco.

(1997b), "Un periódico sefardí: El Meseret de Alexander Ben-Guiat", Sefarad 57, págs. 3-31.

(1993), "Las novelas de El Meseret", Actes del Simposi Internacional sobre Cultura Sefardita, Barcelona: PPU.

BENBASSA, Esther (1986), "Presse d'Istanbul et de Salonique au service du sionisme (1908-1914): Les motifs d'une allégeance", Revue Historique 276, 2 (560), págs. 337-365.

BENBASSA, Esther y ARON RODRIGUE (2004), Historia de los judios sefardies. De Toledo a Salónica, Madrid: Adaba Editores.

BEN-UR, Aviva (2001), "In Search of the American Ladino Press: A Bibliographical Survey, 1910-1948", Studies in Bibliography and Booklore 21, págs. 10-52.

BOROVAYA, Olga (2012), Modern Ladino Culture: Press, Belles Lettres and Theater in the Late Ottoman Empire, Indiana: University Press.

BUNIS, David M. (1999a), Voices from Jewish Salonika: Selections from the Judezmo Satirical Series Tio Ezrá I Su Mujer Benuta and Tio Bohor I Su Mujer Djamila by Moshé Cazés, Jerusalén: Thessaloniki.

(1999b), «Tío Ezrá i su mujer Benuta: Notes on a Popular Series Published in the Saloniki Judezmo Press between the World Wars» en R. Gatenio, ed., Internacional Conference, Judeo Espaniol: The Evolution of a Culture, Thessaloniki: Ets Ahaim Foundation, págs. 49-56.

(1992), "The Earliest Judezmo Newspapers: Sociolinguistic Reflections", Mediterranean Language Review 6, págs. 7-66.

(1990-1993), "The earliest Judezmo newspapers: sociolinguistic reflections", en A. Borg, ed., Special issue commemorating the 5th centenary of the expulsion of the Jews form Spain: 1492-1992, Mediterranean Language Review 6-7, págs. 8-61.

BÜRKI, Yvette (2010), "La Época y El Avenir. Dos periódicos: dos discursos en contraste", en Paloma Díaz-Mas y María Sánchez-Pérez, eds., Los sefardíes ante los retos del mundo contemporáneo. Identidad y mentalidades, Madrid: CSIC, págs. 159-170.

(2006), "El discurso periodístico de la prensa judeoespañola del siglo XIX", Revista Internacional de Lingüística Iberoamericana 8, págs. 53-76.

COHEN, Dov (en prensa), "Un bien conocido negociante i luchador comunal: muevas noticias sobre Rafael Uziel (1816-1881), precursor de la prensa en judeoespañol”, en Rosa Sánchez y Marie-Christine Varol, eds., La presse judéo-espagnole, support et vecteur de la modernité, Estambul: Libra. 
DAGKAS, Alexandros (2003), Recherches sur l'histoire sociale de la Grèce du Nord. Le mouvement des ouvriers du tabac 1918-1928, París: Association Pierre Belon. DÍAZ-MAS, Paloma (2006), Los sefardies. Historia, lengua y cultura, Barcelona: Riopiedras.

DÍAZ-MAS, Paloma y Amelia BARQUÍN (2007), "Relaciones entre la prensa española y la prensa sefardí a finales del siglo xix: El caso de El Luzero de la Pasensia", en Pablo Martín Asuero \& Karen Gerson Şarhon, eds., Ayer y hoy de la prensa en judeoespañol, Turquía: Isis, págs. 37-45.

DÍAZ-MAS, Paloma y Cristina MARTÍNEZ GÁLVEZ, (2013), "Viena como referente en el periódico El Luzero de la Pasensia de Turnu-Severin (1885-1888)", en Michael Studemund-Halévy, Christian Liebl e Ivana Vučina, eds., Sefarad an der Donau, Barcelona: Tirocinio.

DÍAZ-MAS, Paloma y María SÁNCHEZ-PÉREZ, (2014) "Prensa sefardí manuscrita: el periódico judeoespañol El Mesajero/The Messenger (Los Ángeles, 193335)", Ladinar. Estudios sobre la literatura, la música y la historia de los sefardies VII-VIII (2014), págs. 81- 93.

(2012), "La comunidad sefardí de Los Ángeles (California) y su periódico El Mesagero / The Messenger", eHumanista 20, págs. 153-171. Disponible en la siguiente dirección electrónica: http://www.ehumanista.ucsb.edu/volumes/ volume_20/pdfs/articles/monographic\%20issue/8\%20DiazMas-SanchezPerez. v20.pdf

eds., (2010), Los sefardies ante los retos del mundo contemporáneo. Identidad y mentalidades, Madrid: CSIC.

DUMONT, Paul (2001), "Naissance d'un socialisme ottoman", en Gilles Veinstein, ed., Salonique 1850-1918. La "ville des Juifs" et le réveil des Balkans, París: Autrement, págs. 195-207.

GAON, Moshe D. (1965), A Bibliography of the Judeo-Spanish (Ladino) Press, [en hebreo], Jerusalén: Ben-Zvi Institute \& The Hebrew University.

(1937), Yehudé hamizra beeres Yisrael, Jerusalén: Azriel, 2 vols.

GERSON ŞHARON, Karen (2007), "El Amaneser, suplemento mensual del jurnal Şalom", en Pablo Martín Asuero \& Karen Gerson Şarhon, eds., Ayer y hoy de la prensa en judeoespañol, Turquía: Isis, págs. 87-90.

GROSMAN, Moshe (2007), "La prensa judía ke aparesiya kon letras de rashi en Turkia en los anyos 1930-1931: Avram Leyon i la fondasyon del semanal Şalom", en Pablo Martín Asuero \& Karen Gerson Şarhon, eds., Ayer y hoy de la prensa en judeoespañol, Turquía: Isis, págs. 77-81.

GÜLERRYÜZ, Naim (2007), "Historia de la prensa judía turka", en Pablo Martín Asuero \& Karen Gerson Şarhon, eds., Ayer y hoy de la prensa en judeoespañol, Turquía: Isis, págs. 71-76.

HASSÁN, Iacob M. (1966), "El estudio del periodismo sefardí”, Sefarad 26, págs. 229-235 (reseña del libro, en hebreo, de Moshe D. Gaon [1965]).

KEREM, Yitzchak (2003), "The development of the Judeo-Spanish press in Salonika, 1864-1941. A vehicle for modernization and enhanced Sephardic identity", Neue Romania 28, págs. 155-167. 
LEVI, Avner (1983), “El jurnalizmo djudio en Izmir”, Aki Yerushalayim 16, págs. 7-10.

LEVY, Sam (2000), Salonique à la fin du XIXe siècle. Memoires, Estambul: Les Éditions Isis.

LOCHOW-DRÜKE, Christine H. (2007), "La campaña a favor de la propagación del idioma turco entre los sefardíes", en Pablo Martín Asuero y Karen Guerson Şharon, eds., Ayer y hoy de la prensa en judeoespañol, Turquía, Isis, págs. 59-70.

MARTÍNEZ-GÁLVEZ, Cristina (2010), "El Plato de Purim (1909-1910), suplemento satírico del periódico El Avenir", en Paloma Díaz-Mas y María Sánchez-Pérez, eds., Los sefardies ante los retos del mundo contemporáneo. Identidad y mentalidades, Madrid: CSIC, págs. 171-181.

(2009), "La prensa sefardí en Rumanía: contenidos del periódico El Luzero de la Pasiensia (Turnu-Severin, 1885-1888)", Revista de Filología Románica 26, págs. 205-227.

MAZOWER, Mark (2009), La ciudad de los espíritus: Salónica desde Suleimán el Magnifico hasta la ocupación nazi, Barcelona: Crítica.

MOLHO, Michael (1960), Literatura sefardita de Oriente. Madrid, CSIC.

MORCILLO, Matilde (2007) "España y la prensa judeo-española de Salónica durante el primer tercio del siglo XIX", en Pablo Martín Asuero y Karen Guerson Şharon, eds., Ayer y hoy de la prensa en judeoespañol, Turquía, Isis, págs. 47-57.

NASSI, Gad, ed., (2001), Jewish Journalism and Printing Houses in the Ottoman Empire and Modern Turkey, Istanbul: The Isis Press.

PULIDO, Ángel (1904), Los israelitas españoles y el idioma castellano, Madrid: Sucesores de Rivadeneyra.

QUATAERT, Donald (1992), "Premières fumées d'usines"en Gilles Veinstein, ed., Salonique, 1850-1918. "La ville des Juifs" et le réveil des Balkans, París: Éditions Autrement, págs. 177-194.

RIEDER-ZELENKO, Elena (2013), Novedades de Esmirna. Edición de noticias publicadas en el periódico judeoespañol 'La Buena Esperanza' en 1905, Barcelona: Tirocinio.

(2008), "Un periódico judeoespañol en los umbrales del siglo xx: aspectos del léxico de la medicina", Boletín Hispánico Helvético 12, págs. 109-122.

ROMERO, Elena (2010), "La polémica sobre el judeoespañol en la prensa sefardí del Imperio otomano: más materiales para su estudio", Sefarad 70: 2, págs. 435-473. (2007), "La prensa judeoespañola contra los recelos, la burocracia y la censura", en Pablo Martín Asuero \& Karen Gerson Şarhon, eds., Ayer y hoy de la prensa en judeoespañol, Turquía: Isis, págs. 9-35.

(1992), La creación literaria en lengua sefardí, Madrid: MAPFRE.

(1983), Repertorio de noticias sobre el mundo teatral de los sefardies orientales. Madrid: CSIC.

(1979), El teatro de los sefardies orientales, Madrid: CSIC.

SABA-WOLFE, Rachel (2010), "The journal La Buena Esperansa and its battle for reforms in the Jewish community of Izmir", en Paloma Díaz-Mas y María 
Sánchez- Pérez, eds., Los sefardies ante los retos del mundo contemporáneo. Identidad y mentalidades, Madrid: CSIC, págs. 141-148.

SÁNCHEZ-PÉREZ, María (2014), Prensa sefardi de pasatiempo en Salónica. Un "Konsejero" (1913) y dos "Martios" (1914 y 1927), Barcelona: Tirocinio.

(2011), "Yerushalayim, suplemento de El Liberal: una revista sefardí de comienzos del siglo xx", Miscelánea de Estudios Árabes y Hebraicos. Sección hebreo 60, págs. 223-241.

SAVARIEGO, Berta y José SÁNCHEZ-BOUDY (1987), Vida y cultura sefardita en los poemas de "La Vara" (del ladino al español), Miami: Universal.

SCHMID, Beatrice (2003), "Dos números del periódico El Avenir", en Beatrice Schmid, dir., "Sala de Pasatiempo": Textos judeoespañoles de Salónica impresos entre 1896 y 1916, Basilea: Universität Basel, Romanisches Seminar, mayo 2003 $=A R B A$ 14, págs. 85-124.

SHAUL, Moshe (1996), "La prensa djudeo-espanyola en muestros días", Aki Yerushalayim 17,53 , págs. 32-34.

ŠMID, Katja (2010), "Gaćetero vienés vs. rabino saraylí: el inicio de una polémica", en Paloma Díaz-Mas y María Sánchez-Pérez, eds., Los sefardies ante los retos del mundo contemporáneo. Identidad y mentalidades, Madrid: CSIC, págs. 149-158.

STUDEMUND-HALÉVY, Michael, Christian LIEBL e Ivana VUČINA, eds., (2013), Sefarad an der Donau, Barcelona: Tirocinio.

WEICH-SHAHAK, Susana (2010), “A trenta groshes kavé: referencias cotidianas del repertorio sefardí de Oriente”, en Paloma Díaz-Mas y María Sánchez-Pérez, eds., Los sefardies ante los retos del mundo contemporáneo. Identidad y mentalidades, Madrid: CSIC, págs. 225-236.

\section{Notas}

1 Como ejemplo clarificador de esa censura puede verse el fragmento que recoge Elena Romero del libro de Isac Gabay, Yildiz y sus secretos (Romero 2007: 26-28).

2 Este artículo es producto del proyecto de investigación FFI2012-31625, "Los sefardíes ante sí mismos y sus relaciones con España III. Hacia la recuperación de un patrimonio cultural en peligro" del Ministerio de Economía y Competitividad. Así mismo, se ha podido realizar gracias a la concesión de una Schweizer Bundesstipendien für postgraduierte ausländische Studierende und Kunstschaffende, en la Universidad de Basilea (Suiza).

3 Refael Uziel Pincherle (1816-1881) fue un periodista de Esmirna que publicó el primer periódico en judeoespañol aljamiado que se conoce (Véanse: Pulido 1904: 98; Levi 1983; Bunis 1992; Romero 1992: 181; Díaz-Mas y Sánchez-Pérez 2010: 46, 142) Datos tomados de Sefardiweb del CSIC (http:// www.proyectos.cchs.csic.es/sefardiweb/node/801).

4 Al final del trabajo incluimos un glosario donde se explican aquellas palabras que pueden resultar de difícil comprensión; restituimos entre corchetes las palabras que están borrosas o poco legibles debido al mal estado de los originales. Dado que los textos que ofrecemos al lector son transcripciones de originales aljamiados (esto es, judeoespañol escrito con caracteres hebreos), señalamos 
a continuación el sistema de transcripción utilizado y las equivalencias gráfico-fonéticas: $b$ bilabial oclusiva sonora $/ \mathrm{b} / ; v$ bilabial fricativa sonora; $d j$ prepalatal africada sonora $/ \hat{\mathrm{y}} / ; h$ uvular fricativa sorda $/ \mathfrak{i} / ; j$ prepalatal fricativa sonora $/ \check{z} / ;$ ly lateral palatal $/ \lambda /$, que la mayor parte de las veces se realiza en judeoespañol como $/ \mathrm{y} / ; n y$ nasal palatal $/ \mathrm{y} / ; s$ alveolar fricativa sorda $/ \mathrm{s} / ; z$ alveolar fricativa sonora $/ \mathrm{z} / ;$ sh prepalatal fricativa sorda $/ \check{\mathrm{s}} / ; t s$ alveolar africada sorda $/ \hat{\mathrm{s}} /$. Puntuamos, acentuamos y versalizamos los textos que citamos. Para la presente investigación hemos manejado textos que proceden de microfilmes de la Biblioteca Nacional de Israel y de fotografías digitales de periódicos sefardíes, tomadas directamente a partir de los originales que se hallan en la biblioteca del Instituto Ben Zvi (Jerusalén).

5 Aarón Iosef Hazán (1848-1931) fue un periodista y escritor de Esmirna. Descendiente de una conocida familia de rabinos combinó una postura de respeto religioso junto con una actitud innovadora hacia la educación como instrumento de modernización. Durante cincuenta años enseñó turco en el Talmud Torá de Esmirna y, posteriormente, en la Alliance Israélite Universelle. Escribió novelas y obras de teatro, y también adaptó otras de la literatura occidental (Véanse, Gaon 1937: 245; Romero 1992: 181, 240, 278, 286, 287; Saba-Wolfe 2010). Información tomada de Sefardiweb del CSIC (http://www.proyectos.cchs.csic.es/sefardiweb/node/311), donde pueden encontrarse más datos.

6 Alexandre Ben-Guiat (1869?-1924?/1934?) fue un prolífico escritor y periodista de Esmirna. Publicó diferentes periódicos -alguno de ellos muy longevos, como El Meseret-y suplementos. Publicó tanto traducciones y adaptaciones de novela popular como versiones reducidas de grandes obras de la literatura europea. Escribió también para el teatro pequeñas comedias de costumbres, en las que incluso llegó a participar como actor. (Para más información, Barquín 1997a, 1997b y 2007). Consúltense más datos en Sefardiweb del CSIC (http://www.proyectos.cchs.csic.es/sefardiweb/node/51).

7 Se refiere a un número anterior que no se ha conservado.

8 Sin embargo, en la cabecera se declara otro precio: “Abonamientos: Esmirna y Turkía, 2 medjediés; Europa, 12 frankos".

9 Sa‘adi Haleví (¿-1908?) fue un periodista, impresor y activo participante de la comunidad de Salónica. Fue también compositor e impresor de coplas sefardíes, tanto de contenido noticiero como satírico o relacionado con la celebración de festividades litúrgicas. Información tomada de Sefardiweb del CSIC (http://www.proyectos.cchs.csic.es/sefardiweb/node/266), donde pueden encontrarse más datos.

10 Sam Levy (1870-1959) fue un periodista y escritor de Salónica, hijo de Sa 'adi Haleví. Estudió en las escuelas de la Alliance Israélite Universelle y también Letras en la Sorbona. Fue corresponsal también de Ángel Pulido, a quien describe la situación de la lengua judeoespañola de su ciudad. Uno de sus artículos fue contestado por Rafael Cansinos Assens en el Journal de Salonique (1904), mostrando su adhesión a las opiniones de Sam Levy sobre la no pertinencia de rehispanizar el judeoespañol. Información tomada de Sefardiweb del CSIC (http://www.proyectos.cchs.csic.es/sefardiweb/node/736), donde pueden encontrarse más datos. Cabe destacar su libro de memorias Levy 2000.

11 Eliyahu Shem Tob Arditi (1875-i) fue un escritor, traductor, publicista y dramaturgo de Salónica. Para más datos véase Sefardiweb del CSIC (http://www.proyectos.cchs.csic.es/sefardiweb/node/39).

12 (tr. Padisahimiz cok yasa) ‘¡muchos hurras por el sultán!’.

13 David Isaac Florentín (1875-¿) fue un periodista de Salónica y dirigente sionista que emigró a Israel en 1926. Pueden verse más datos en la página de Sefardiweb del CSIC (http://www.proyectos.cchs. csic.es/sefardiweb/node/223).

14 El Avenir tuvo, además, otro suplemento: El Plato de Purim (Martínez-Gálvez, 2010).

15 No es la primera vez que las páginas de los periódicos sefardíes sirvieron de vehículo para expresar, pero también confrontar posturas e intereses sobre diversos aspectos que afectasen a sus comunidades: ideas políticas, pero también debates sobre la modernización de la sociedad sefardí, enfren- 
tamientos ideológicos y lingüísticos, etc. Como ejemplos pueden verse: Bürki 2010, Šmid 2010, y Romero 2010.

16 Abraham Ben-Aroya fue un impresor, traductor y sindicalista de Salónica. Para más datos y referencias bibliográficas véase Sefardiweb del CSIC (http://sefardiweb.com/node/59).

17 Es importante destacar que el socialismo penetró en el mundo judío precisamente gracias a los sefardíes y "la educación socialista se impartía en la lengua vernácula, el judeoespañol" (Benbassa y Rodrigue 2004: 310).

18 Recordemos que Salónica se convirtió en un centro muy destacado en la producción y comercialización de tabaco en aquella época. Sobre la industrialización de Salónica, véanse, entre otros, Quataert 1992; y Dagkas 2003.

19 Benbassa y Rodrigue señalan: "El antisemitismo de los años treinta en Salónica se confundía con el anticomunismo. Por aquellas fechas, los judíos eran asociados con el comunismo" (2004: 239).

20 La noche del 29 de junio de 1931 hubo un incendio en el barrio judío y unas quinientas familias se vieron sin hogar en pocas horas. Esto desató el pogromo y, aunque afortunadamente solamente hubo una víctima, fueron profanadas varias tumbas del cementerio judío de Salónica.

21 Recuérdese, de nuevo, el trabajo de Abrevaya Stein 2004 donde comparaba el periódico en yidish Der fraynd y el judeoespañol El Tiempo. 